\section{Costs and Benefits of Implementing Sensor-controlled Irrigation in a Commercial Pot-in-Pot Container Nursery}

\author{
Bruk E. Belayneh ${ }^{1}$, John D. Lea-Cox ${ }^{1,3}$, and Erik Lichtenberg ${ }^{2}$
}

ADDITIONAL INDEX WORDs. decision irrigation, dogwood, red maple, return on investment, sensor networks, soil moisture, web based

SUMMARY. Irrigation scheduling in ornamental plant production is complex due to the large number of species grown by individual growers and the need to consider plant, environment, and substrate conditions to make correct irrigation decisions on a daily or more frequent basis. The engineering team in our project has developed a smart wireless sensor node that is capable of integrating outputs from a range of soil moisture and environmental sensors to schedule irrigation events. In addition, an advanced monitoring and control software enables growers to manage irrigation based on set-point or model-based protocols, which are then independently executed by the nodes, enhancing or replacing human decision making. During 2012, we implemented a sensor-controlled vs. grower-controlled irrigation study at a pot-in-pot nursery in Tennessee. Sensor networks were installed in two separate production blocks of 3-year-old dogwood (Cornus florida 'Cherokee Brave') and 2-year-old red maple (Acer rubrum 'Autumn Blaze') trees grown in 15- and 30-gal containers, respectively. One row of trees in each block was irrigated based on the average reading of soil moisture sensors inserted in individual trees using micropulse irrigation, i.e., sensor controlled. Trees in the adjacent row and the rest of the block were independently irrigated by the grower using standard practices, i.e., grower controlled. Sensor volumetric water content (VWC) readings and irrigation volumes were logged by nodes on a $15-\mathrm{min}$ basis and were relayed to a base station on the farm. For the study period between Mar. 2012 and Nov. 2012, average daily water applied by the grower-controlled irrigation to the dogwood block was $0.92 \mathrm{gal} / \mathrm{tree}$, compared with $0.34 \mathrm{gal} /$ tree applied using sensor-controlled irrigation; for red maple, these values were $1.72 \mathrm{gal} /$ tree and $1.13 \mathrm{gal} / \mathrm{tree}$, respectively. No significant differences in tree caliper or quality were noted between the two irrigation treatments in either species over the year. The cost of water for this particular operation was negligible consisting only of pumping costs, as water is drawn from a perennial stream with excellent water quality. Consequently, a conservative return on investment for a wireless sensor network capable of covering the entire operation was $37.5 \%$, corresponding to a payback period of 2.7 years, associated almost entirely from a reduction in irrigation management time. Pricing in a nominal cost for water of $\$ 326$ per acre-foot $(\$ 1$ per 1000 gal) increased annualized net savings 9 -fold, reducing the payback period to less than 4 months. This analysis did not factor in additional economic benefits such as reductions in production time, losses due to disease, or increased plant quality, which have been associated with the use of sensor-based irrigation control in other studies.

A utomated irrigation scheduling systems are widely used in intensive horticultural production environments, such as greenhouse,

This paper is part of a series of manuscripts describing the research and development completed by the SCRI-MINDS (Managing Irrigation and Nutrition through Distributed Sensing) project. The authors gratefully acknowledge funding and support from the USDA-NIFA Specialty Crops Research Initiative; Award \#2009-51181-05768.

We sincerely thank Terry Hines for his assistance.

${ }^{1}$ Department of Plant Science and Landscape Architecture, University of Maryland, College Park, MD 20742-4452

${ }^{2}$ Department of Agricultural and Resource Economics, University of Maryland, College Park, MD 207425535

${ }^{3}$ Corresponding author. E-mail: jlc@umd.edu. container nursery, or field ornamental nurseries. Additionally, many high-value food crops are also irrigated, as are golf-courses and high-value landscape settings. Currently, most growers of horticultural crops base their irrigationscheduling decisions on intuition or experience (Bacci et al., 2008; Jones, 2008 ) using time-based programmable devices or by using more sophisticated irrigation-scheduling tools such as evapotranspiration (ET) models or soil-moisture sensing devices. The first question that a grower or manager needs to answer is whether they need to irrigate at that specific time. Typically, the next question is how long do they need to irrigate to ensure adequate water is available for the plant? Although these questions could seem trivial, plant water requirements vary by species, plant size, rooting volume, season and microclimate, and depend upon any number of environmental and plant developmental factors that need to be integrated on a day-to-day basis (Lea-Cox, 2012 ). If you then consider the number of species grown in a "typical" nursery or greenhouse operation [often $>250$ species (Majsztrik et al., $2011)$ ], the variety of container sizes (i.e., rooting volume, water-holding capacity), and the length of crop cycles, it quickly becomes obvious why irrigation scheduling in ornamental operations becomes complex, if it is to be achieved with any level of precision (Lea-Cox et al., 2001; Ross et al., 2001).

Although experiential methods for scheduling irrigations can achieve good results, they tend to be subjective with different operators making different decisions. Many times, even experienced managers make an incorrect decision; i.e., they irrigate when water is not required by the plant or do not irrigate when it is needed. It is also surprising how many so-called "advanced" irrigation controllers, which allow operators to program complex scheduling routines merely automate irrigation cycles on the basis of time, without any feedbackbased control systems. Thus, even with advanced time-based systems, the decision to irrigate is again based solely on the operator's judgment and the time

\begin{tabular}{lllc}
\hline $\begin{array}{l}\text { Units } \\
\text { To convert U.S. to SI, } \\
\text { multiply by }\end{array}$ & U.S. unit & SI unit & $\begin{array}{l}\text { To convert SI to U.S., } \\
\text { multiply by }\end{array}$ \\
\hline 0.4047 & acre(s) & ha & 2.4711 \\
0.1233 & acre-foot & hectare-meter & 8.1071 \\
0.0283 & $\mathrm{ft}^{3}$ & $\mathrm{~m}^{3}$ & 35.3147 \\
3.7854 & gal & $\mathrm{L}$ & 0.2642 \\
0.0038 & gal & $\mathrm{m}^{3}$ & 264.1721 \\
2.54 & inch(es) & $\mathrm{cm}$ & 0.3937
\end{tabular}


taken to evaluate crop water use and integrate other information, e.g., weather conditions during the past few days and in the immediate future (Lea-Cox, 2012).

Many sensor technologies have been developed and used over the years to aid irrigation scheduling decisions. Various soil moisture measurement devices are available, e.g., tensiometers, gypsum blocks and meters, which directly sense soil moisture (van Iersel et al., 2013). Additionally, pan evaporation and weather station or satellite forecast data can be incorporated into ET models, such as the Penman-Monteith model which is widely used in agronomic crops (Fereres et al., 2003), where specific crop coefficient $(\mathrm{Kc})$ values have been calculated and validated. However, the widespread adoption of most of this technology has not occurred in the nursery and greenhouse industries for good reasons. Many sensing technologies that were originally engineered for soil-based measurements have been applied to soilless substrates. Many have failed, largely because these sensors did not perform well in highly porous substrates, since porosity is an important physical property that is necessary for good root growth in containers (Bunt, 1961). Even when a technology has been adapted successfully to container culture (e.g., low-tension tensiometers), the technology has often been too expensive for wide-scale adoption, difficult to automate, or there have been precision, reliability, and/or maintenance issues. For most growers, initial cost and ease of use are key aspects to the adoption and use of any tool, since they usually do not have the time or the labor to devote to the maintenance of less-robust tools.

The objectives of this study were 1) to test a new advanced wireless sensor technology in a commercial pot-in-pot nursery production environment and 2) to provide a basic cost-benefit analysis for the sensor network installed in this nursery. Specifically, we tested the reliability and precision of a new control node (nR5; Decagon Devices, Pullman, WA) that independently controlled irrigation in two blocks of trees during 2012, with minimal human intervention. This was achieved by using average substrate VWC readings for the initiation of irrigation events below a set-point/ threshold value. Additionally, we fully tested the functionality of an advanced "Sensorweb" software (Kohanbash et al., 2013), which allowed for straightforward irrigation control programming and the monitoring of weather, substrate VWC, and flow meter data via a dedicated website for the farm. Lastly, to calculate simple returns on investment, we gathered resource use data for water, pumping, labor and equipment costs associated with these activities.

\section{Materials and methods}

SENSOR NETWORK HARDWARE AND SOFTWARE. We have deployed and used commercially available wireless sensor nodes (Em50R, Decagon Devices) and various sensors in this nursery since 2009. These nodes have been used to monitor data from a variety of soil moisture and environmental sensors in various production areas. The data collected from all sensors is transmitted from each Em50R node (using a $900-\mathrm{MHz}$ radio card) to a base station connected to a personal computer on the farm. The incoming data are collected and stored in a database; software (Datatrac, Decagon Devices) then plots and graphically displays the sensor information from each node. Nodes and production blocks can be organized within the software for ease of access. Incoming data from each node is organized and is appended to the database and graphically displayed at various time scales, depending on what question the grower/user wants to answer. For example, what is the current soil moisture status in a particular block/species? What has been the trend in this block of soil electrical conductivity (EC) in the past 3 months?

CONTROL NODE IMPLEMENTATION. Kohanbash et al. (2013) provide an extensive review of the development and functionality of the $\mathrm{nR} 5$ node and the Sensorweb software, which provides a control capability, rather than just a monitoring capability with the Em50R nodes. The two versions of the nR5 nodes-nR5-AC and nR5$\mathrm{DC}$ - can operate alternating current (24-V AC) or direct current (12-V DC latching) solenoids, respectively. Five size AA alkaline batteries provide sufficient power for a single nR5-DC node to operate $12-\mathrm{V}$ DC latching solenoids, increasing the utility of these nodes for automatically controlling irrigation events in remote production blocks where there is no power (Kohanbash et al., 2011). The nR5-DC nodes were exclusively used in this study. Irrigation control is achieved by interfacing the nR 5 nodes with the Sensorweb software (Kohanbash et al., 2012, 2013).

The Sensorweb software provides a custom website associated with the wireless sensor network on the farm (Fig. 1). It provides growers with a range of irrigation control modes (Kohanbash et al., 2013); this irrigation scheduling flexibility gives a grower the ability to precisely control how water gets applied to an irrigation zone with various user-defined parameters. The user can choose between a mode where water will be applied slowly, with small delays between irrigation events that allows water to reach the subsurface sensors (micropulse irrigation) (Lea-Cox et al., 2009) or a mode in which water is applied continuously for a specified period of time. These modes of action are based on operational requirements (e.g., different substrates, species have different water use) or grower preference. These are discussed in detail by Kohanbash et al. (2013) and illustrated by this study.

SENSOR-CONTROLLED IRRIGATION STUDY. This large (175 acres) pot-inpot nursery produces a wide range of tree and shrub species in 10-, 15-, 30-, and 45-gal containers. Since rooting volumes are relatively limited, and due to the porous soilless substrate mix used, irrigation scheduling needs to be much more frequent with lower volumes per irrigation event, compared with growing similar species in field soils. Leaching of nutrients from containers is also likely without careful irrigation scheduling, regardless of the type of fertilizer used.

Two separate grower-controlled vs. sensor-controlled irrigation studies were started in Mar. 2012-one in a block of dogwood trees and the other in a block of red maple trees (Fig. 2A). There were 133 trees in both the grower-controlled and sensor-controlled row for dogwood, whereas for red maple, there were 61 trees in the grower-controlled row compared with 59 in the sensorcontrolled row. The irrigation line for the sensor-controlled row in each block was plumbed directly from the mainline to provide independent 


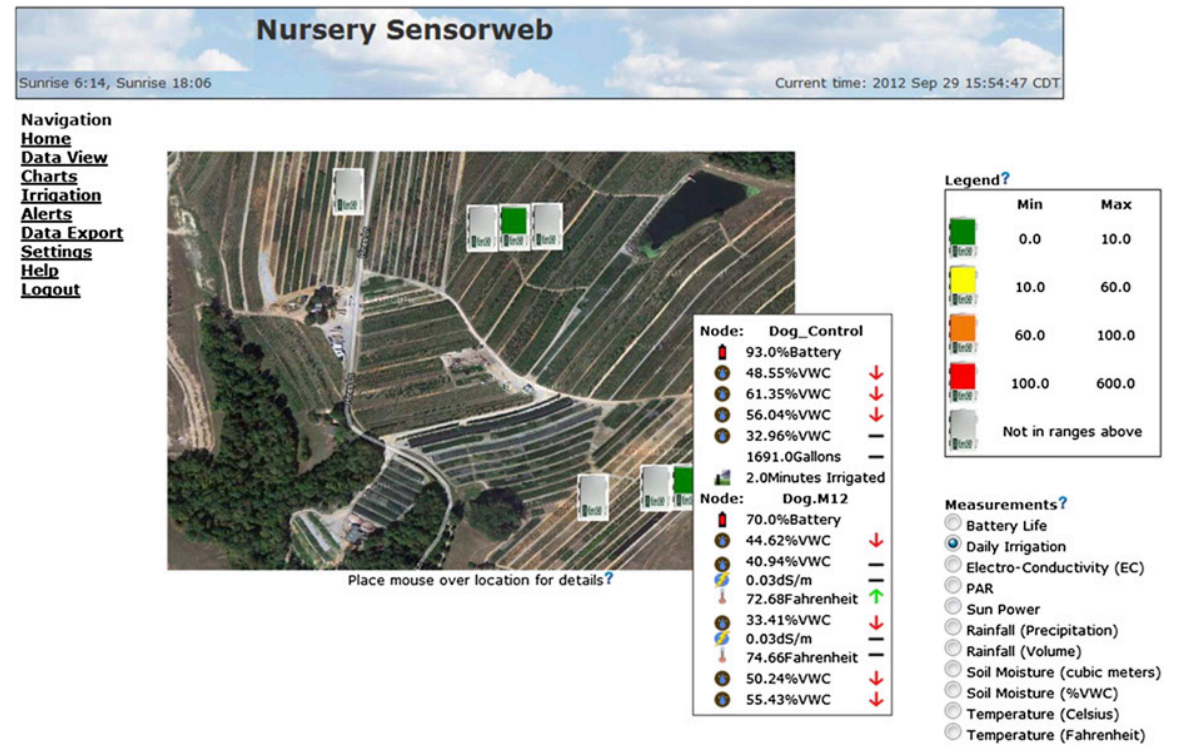

Fig. 1. The Sensorweb (Kohanbash et al., 2013) home page for the wireless sensor network showing various locations where nodes are deployed in the pot-in-pot nursery. Nodes are colored based on the measurement type selected, whereas latest readings can be displayed by placing the cursor over node locations.

irrigation control by the nR5 node (Fig. 2B). A 12-V DC latching solenoid was installed for each sensorcontrolled row and connected to the nR 5 node (Fig. 3 ) to enable set-point irrigation based on 10HS soil moisture sensors (Decagon Devices). Flow meters (model 25; Badger Meter, Milwaukee, WI) were installed for both the grower-controlled and sensorcontrolled rows in each block and connected to the nR5 or Em50R nodes to provide real-time flow data (Fig. 3).

SENSOR PLACEMENT AND CALIBration. The $10-\mathrm{cm}$-long $10 \mathrm{HS}$ soil moisture sensors were installed by pushing them horizontally through a slit on the side wall of the 15-gal dogwood and 30-gal red maple tree containers until they were completely buried in the substrate. For all trees, the sensors were inserted at specific depths to avoid variations in VWC readings due to gravitational drainage effects. All sensors were placed with the blade side of the sensor orientated perpendicular to the surface to avoid any water "shadow" effect on the substrate below. For dogwood, 10HS sensors were inserted at 6-inch depth in four trees in both the growercontrolled and sensor-controlled rows. For red maple, 10HS sensors were inserted at 6-and 12-inch depth in four trees in both the grower-controlled and sensor-controlled rows. Irrigation for the sensor-controlled rows in both

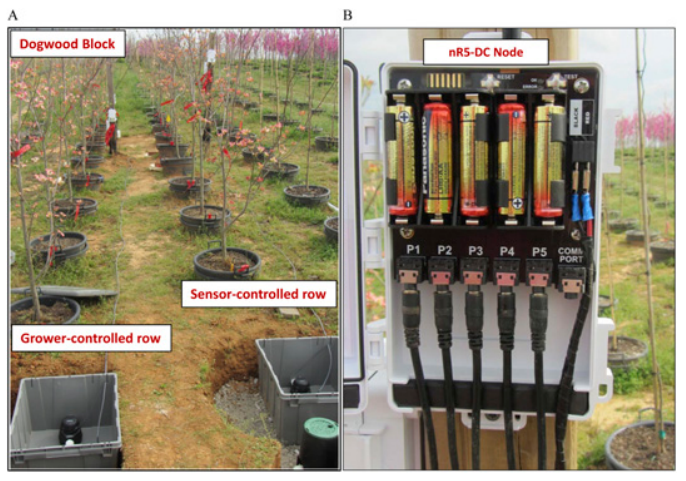

Fig. 2. (A) The dogwood production block showing the grower-controlled and sensor-controlled rows. Grower-controlled rows were irrigated based on timed cyclic irrigation events scheduled by the grower. Sensor-controlled rows were irrigated for a specified amount of time when the average volumetric water content (VWC) reading of four 10HS sensors (Decagon Devices, Pullman, WA) dropped below 46.0\%. (B) The nR5-DC node (Decagon Devices) in tandem with the 12-V DC latching solenoid and 10HS sensors enabled sensor-controlled irrigation.

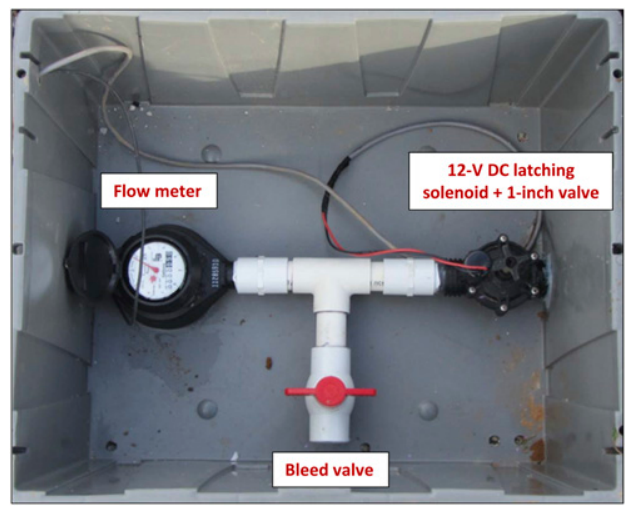

Fig. 3. The 12-V DC latching solenoid valve and Badger flow meter (model 25; Badger Meter, Milwaukee, WI) housed in a protective container; 1 inch $=2.54 \mathrm{~cm}$. 
dogwood and red maple was scheduled based on the average VWC reading of the four sensors at 6-inch depth. The 12-inch depth sensors in red maple were only used to monitor the substrate moisture status at the bottom of the container to ensure that the lower parts of the containers were maintained at similar moisture contents. Before installation, a specific calibration (Fig. 4) for the 10HS sensor and the $75 \%$ pine bark: $25 \%$ recycled paper substrate used by this nursery was performed in our laboratory at the University of Maryland, using a custom calibration procedure for soilless substrates (Cobos and Chambers, 2010).

IRRIGATION SCHEDULING. The grower scheduled all irrigation events from Mar. 2012 through Nov. 2012 on the grower-controlled rows using multiple (cyclic) irrigations, which is currently a best management irrigation practice. No changes were made in irrigation duration from previous years; cyclic irrigation durations were set to $6 \mathrm{~min}$ per cycle and one to four times per day, depending on the season. An example of these timed cyclic irrigation events in June 2012 is shown in Fig. 5. Irrigation events for all growercontrolled trees were programmed through an existing two-wire irrigation control system (Tucor, Wexford, $\mathrm{PA}$ ), which is used to schedule irrigations throughout the farm. Timed irrigation schedules were typically adjusted on a biweekly or weekly basis during summer by the irrigation manager. This program was interrupted by the irrigation manager after any significant rainfall event.

In contrast, the sensor-controlled rows were only irrigated when the average substrate VWC sensed by four 10HS sensors was less than the $46.0 \%$ set-point, i.e., $0.46 \mathrm{~m}^{3} \cdot \mathrm{m}^{-3}$ (Fig. 6). As can be seen from Fig. 4, the $46 \%$ set-point was about at the midpoint of water availability for this pine bark: recycled paper substrate. The micropulse irrigation utility of the Sensorweb software was used (Kohanbash et al., 2011) in such a way that irrigation events in the sensorcontrolled rows were pulsed for only 2-min durations, with a 3-min interrupt period during any 5 -min window the irrigation command is executed. In this way, the relatively large amount of water applied by the yellow spray stake (Netafim USA, Fresno, CA) to each tree $(3 \mathrm{gal} / \mathrm{h})$ could be sensed more effectively by the sensors. When the average VWC reading from the four trees was restored to $46.0 \%$ or above, the irrigation command was skipped. This resulted in much lower average leaching from each tree container (data not shown) while minimizing the irrigation cycle times. It should be noted that irrigation scheduling for the sensor-controlled rows

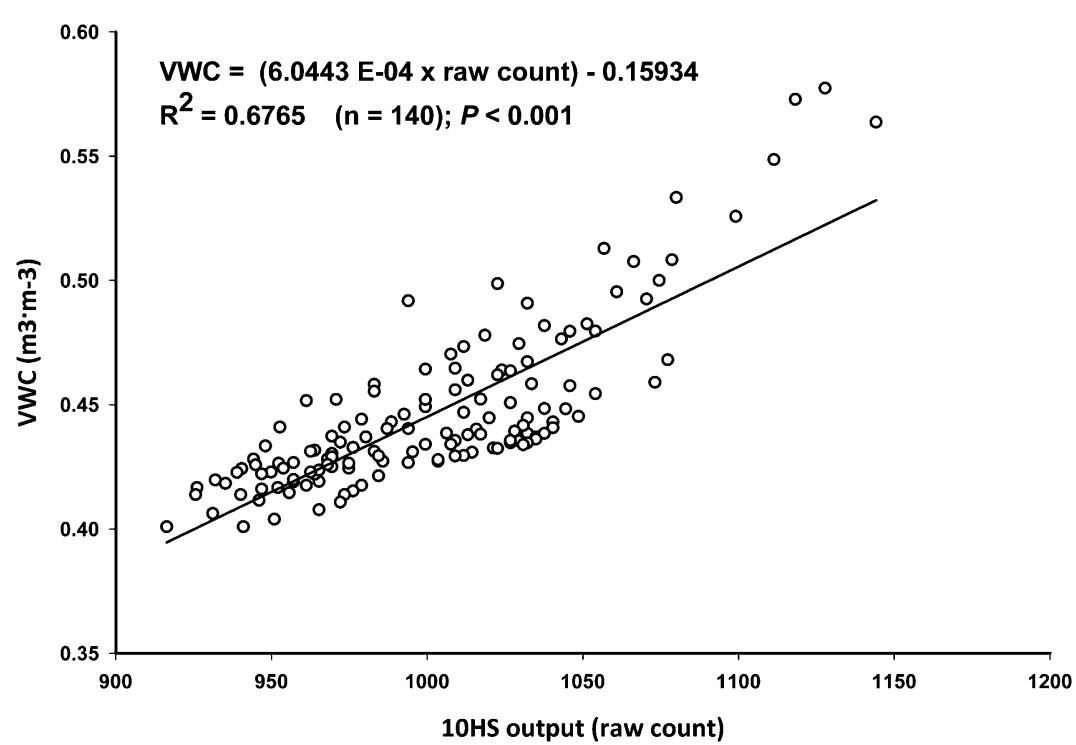

Fig. 4. Calibration curve for the 10HS sensor (Decagon Devices, Pullman, WA) and $75 \%$ pine bark: $25 \%$ recycled paper substrate. The calibration coefficients were entered into Sensorweb (Kohanbash et al., 2013) to convert the 10HS sensor output into volumetric water content (VWC); $1 \mathrm{~m}^{3}=35.3147 \mathrm{ft}^{3}$. was achieved remotely via a website linked to the base station and the onfarm computer in Tennessee. There were very few times that outside intervention by the irrigation manager was necessary, and in those cases, it was merely to make some minor adjustments to sensors.

SENSOR, WATER USE, AND TREE GrowTH DATA. Continuous 10HS sensor VWC and flow meter data were taken on a per minute basis and averaged and logged on a 15-min basis by Em50R or nR5 nodes in each row of the dogwood and red maple blocks (Fig. 7A and B, respectively). Weather data-rainfall/precipitation, photosynthetically active radiation $(P A R)$, temperature and relative humidity, wind (speed and direction), and leaf wetness [with ECRN-100 rain gauge, QSO-S PAR sensor, EHT T/RH sensor, Davis cup anemometer, and Leaf Wetness Sensor, respectively (Decagon Devices)] - also were taken every $1 \mathrm{~min}$ and averaged and logged on a 5 -min basis throughout the year. All data were transmitted to a base station connected to a computer in the farm office. The size AA alkaline batteries were replaced in the $\mathrm{nR} 5$ nodes 4 months into the study, since these nodes provided power to independently control the latching solenoids for daily irrigations. Em50R node batteries were only replaced at the beginning of the experiment (Mar. 2012) and in Spring 2013 for the next year. The diameters of five trees were measured for both the growercontrolled and sensor-controlled rows in each block in Apr., June, Aug., and Nov. 2012. Trunk calipers were measured bidirectionally at 6 -inch height and averaged for each tree. A covariate analysis was performed using SAS (version 9.2; SAS Institute, Cary, NC) to analyze significant differences in tree growth between the growercontrolled and sensor-controlled trees and to account for initial differences in tree diameter between the rows.

Relative PROFITABILITY OF SENSOR-CONTROLLED VS. TIMED IRRIGATION APPLICATION. Wholefarm estimates of the annual savings in expenditures obtained by switching from timed to sensor-controlled irrigation were calculated by multiplying average annual expenditures on water by the average percentage reduction in water use from using sensor-controlled irrigation (Table 1). 


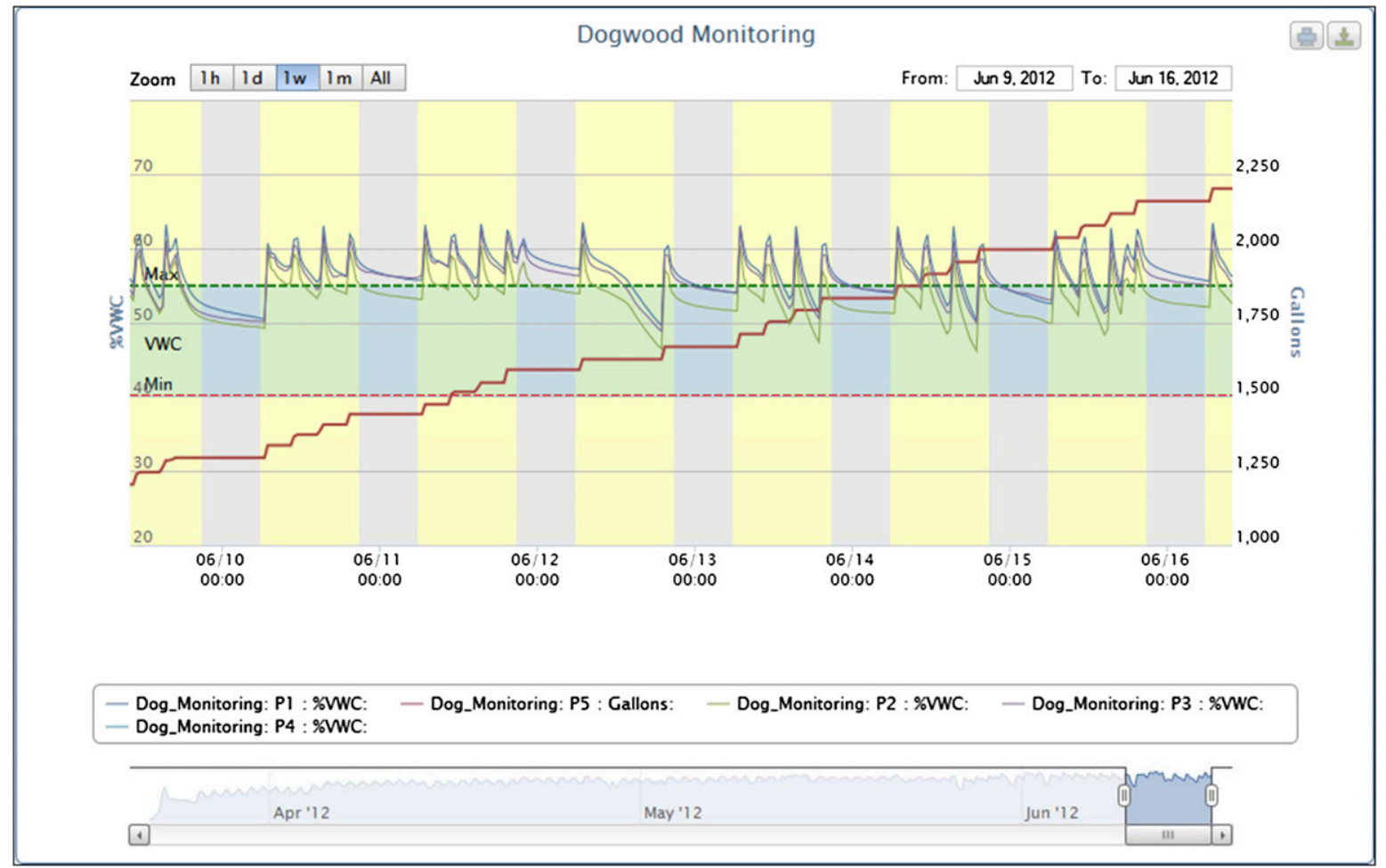

Fig. 5. Substrate volumetric water content (VWC) from 10HS sensors (Decagon Devices, Pullman, WA) in four grower-controlled dogwood trees (left $y$-axis) plotted by Sensorweb (Kohanbash et al., 2013) during June 2012. The red line indicates cumulative water applied per row of 133 trees (right $y$-axis). The timed cyclic irrigation events were scheduled by the grower; 1 gal $=3.7854 \mathrm{~L}$.

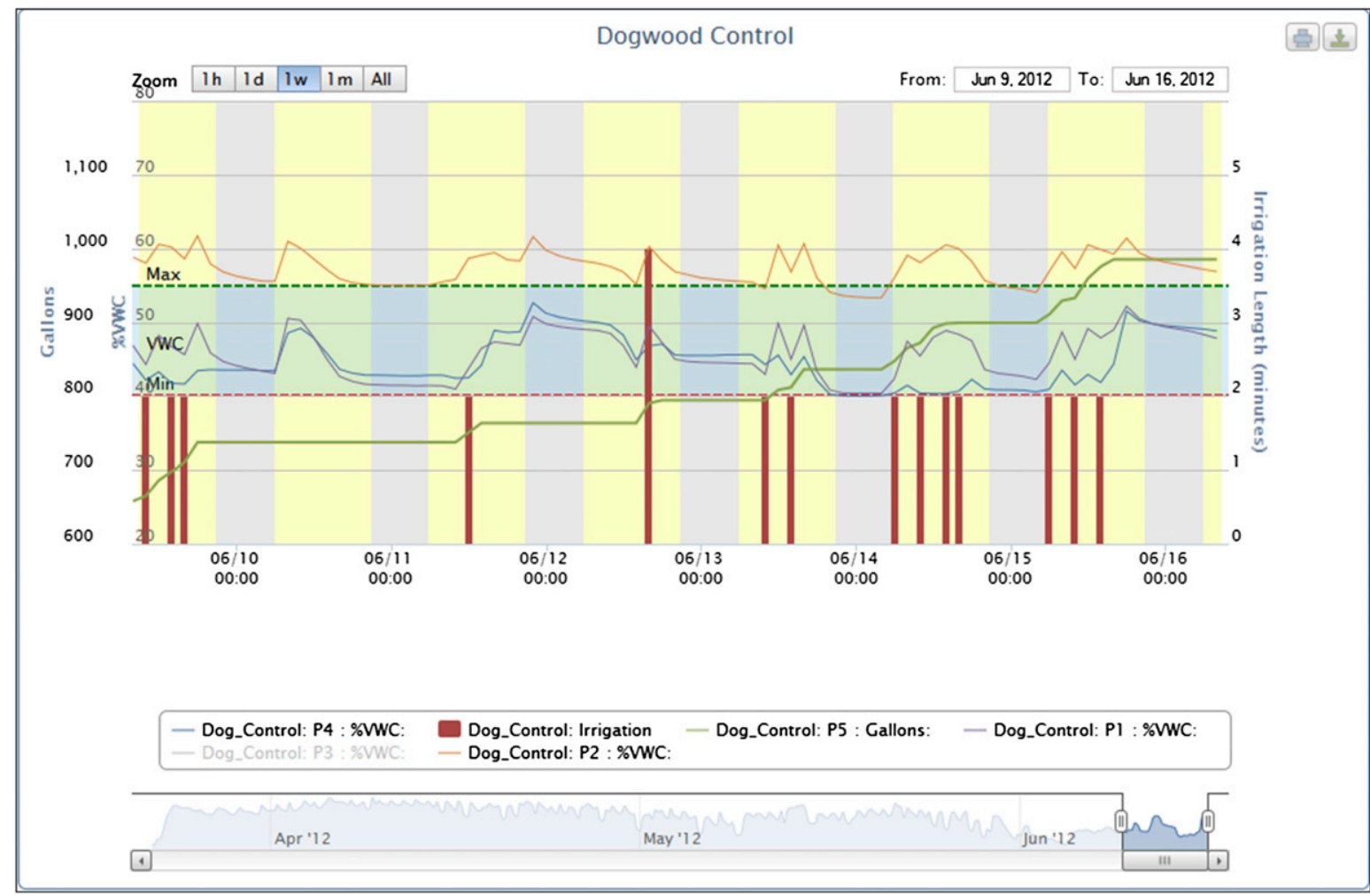

Fig. 6. Substrate volumetric water content (VWC) from 10HS sensors (Decagon Devices, Pullman, WA) in four sensorcontrolled dogwood trees (left $y$-axis) plotted by Sensorweb (Kohanbash et al., 2013) during June 2012. The green line indicates cumulative water applied per row of 133 trees (left $y$-axis), whereas the orange bars represent irrigation events and their length ( $\mathrm{min}$ ). Irrigation was turned on for a specified period of time when the average VWC reading of four $10 \mathrm{HS}$ sensors dropped below $46.0 \%$; 1 gal $=3.7854 \mathrm{~L}$. 


\section{A. Dogwood}

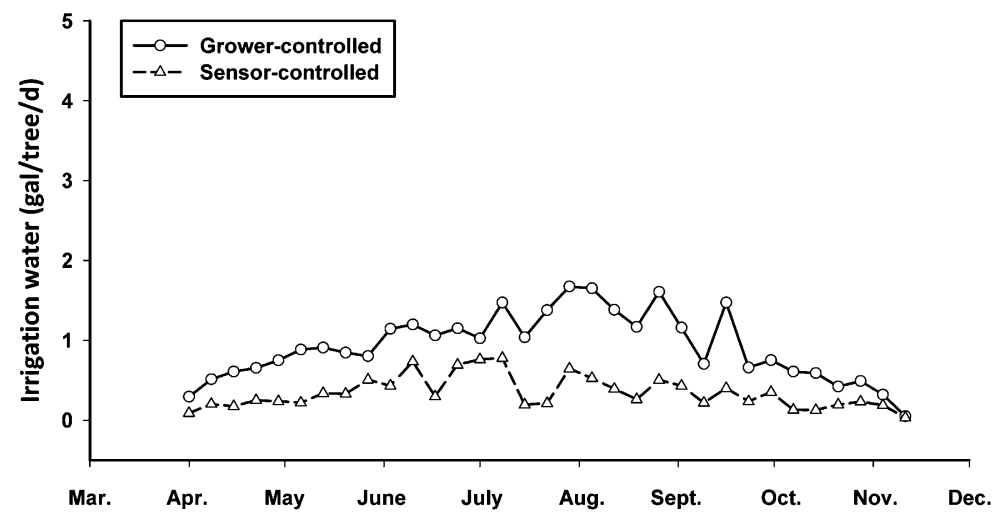

B. Red maple

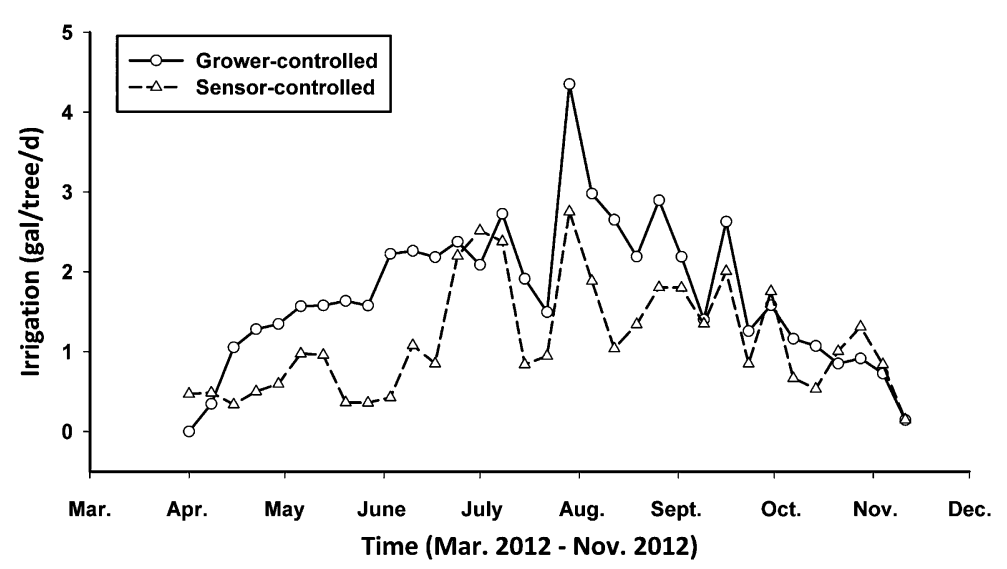

Fig. 7. Average irrigation water applications for (A) dogwood and (B) red maple trees calculated on a weekly basis for the period from 1 Apr. 2012 through 15 Nov. 2012. The grower-controlled trees were irrigated based on timed cyclic irrigation events scheduled by the grower. The sensor-controlled trees received irrigation for a specified duration of time when the average volumetric water content reading of four 10HS sensors (Decagon Devices, Pullman, WA) dropped below the set-point of $46.0 \%$; 1 gal $=3.7854 \mathrm{~L}$.

The nursery inventory was divided into high, medium, and low water use species; the average percentage reduction in water use calculated as a use species, which accounted for $10 \%$ species-weighted average. High water- of the nursery's inventory, were assumed to experience similar reductions in water use as red maple (i.e., $31 \%$ ); low water-use species, which accounted for $51 \%$ of the nursery's inventory, were assumed to experience similar reductions in water use as dogwood (i.e., 63\%); and medium water-use species, which accounted for 39\% of the nursery's inventory, were assumed to require a reduction in water-use intermediate between red maple and dogwood (i.e., 47\%). Overall, switching to sensor-controlled irrigation thus reduced water use by $53.5 \%$. The nursery's pumping cost records were used to calculate average expenditures on water during 2010-12, which equaled $\$ 15,209$. Since water is pumped for the entire nursery from a perennial river with excellent water quality, the real cost of water only includes pumping costs. This is in contrast to many nurseries in the United States, where there are associated costs for purchasing, treating water for water quality issues (filtration, acidification for alkalinity), and/or chlorination for pathogen management from recycled water sources. Note that these costs did not include pump maintenance, which would probably be reduced similarly to the volumes of water pumped per year.

During Spring 2013, the farm sensor network was expanded to provide the capability to monitor and control irrigation events in additional four tree species: two [crepe myrtle (Lagerstromenia indica) and birch (Betula nigra)] in 15-gal and two [red oak (Quercus rubra) and hornbeam (Carpinus betulus)] in 30-gal

Table 1. Summary of total and average water applications by grower-controlled and sensor-controlled irrigation systems for dogwood and red maple trees for the period from 1 Apr. 2012 to 15 Nov. 2012. Grower-controlled rows were irrigated based on timed cyclic irrigation events scheduled by the grower. Sensor-controlled rows were irrigated for a specified amount of time when the average volumetric water content (VWC) reading of four sensors (10HS; Decagon Devices, Pullman, WA) dropped below $46.0 \%$.

\begin{tabular}{|c|c|c|c|c|}
\hline Irrigation method & $\begin{array}{c}\text { Total water } \\
\text { applied }(\text { gal/row })^{\mathrm{z}}\end{array}$ & $\begin{array}{l}\text { Avg water application } \\
(\text { gal/tree } / \text { day })^{y}\end{array}$ & $\begin{array}{c}\text { Avg efficiency } \\
\text { (timed vs. control) }\end{array}$ & $\begin{array}{c}\text { Water savings } \\
\text { (control vs. timed) }\end{array}$ \\
\hline Dogwood:grower controlled & 29,005 & 0.92 & \multirow{3}{*}{0.37} & \multirow{3}{*}{2.69} \\
\hline Dogwood:sensor controlled & 10,770 & 0.34 & & \\
\hline Red maple:grower controlled & 24,184 & 1.72 & & \\
\hline & & & 0.66 & 1.51 \\
\hline
\end{tabular}

${ }^{\mathrm{z}} 1 \mathrm{gal}=3.7854 \mathrm{~L}$.

${ }^{\mathrm{y}}$ Dogwood $=528-\mathrm{ft}$ rows, red maple $=360-\mathrm{ft}$ rows; $1 \mathrm{ft}=0.3048 \mathrm{~m}$.

${ }^{x}$ Dogwood grower-controlled $=133$ trees $/$ row, dogwood sensor-controlled $=133$ trees $/$ row, red maple grower-controlled $=60$ trees $/$ row, red maple sensor-controlled $=$ 59 trees/row. 
containers. This sensor network is composed of nR5 and Em50R nodes and allows for the real-time monitoring of substrate VWC (10HS sensor) and irrigation water applications (Badger flow meter) as well as the measurement of leachate volumes (ECRN-100 rain gauge), leachate EC (ES-2, Decagon Devices), and substrate temperature and EC (GS3, Decagon Devices) from 10 trees in each row. When reconfigured in 2014, this enterprise-wide network will allow for the monitoring and control of irrigation of eight indicator tree species.

The commercial price of nodes, sensors, flow meters, and weather station sensors for this enterprisewide sensor network are shown in Table 2. The cost of the Sensorweb software, base station, and computer equals the cost $( \pm \$ 750)$ of a Windows PC. The cost of installing the hardware was calculated from financial and labor records kept by the nursery (Table 2). B.E. Belayneh and J.D. Lea-Cox provided the total cost of their time spent on setup consultation and installation (two trips to the nursery site). Expenditures on each component were annualized to make them comparable to the annual savings in water and irrigation management costs. Hardware and setup costs were annualized at an interest rate of $6 \%$, the approximate rate paid by small businesses reported by the National Federation of Independent Businesses as of Dec. 2012 (Dunkelberg and Wade, 2013). All of the equipment was assumed to have a 3-year lifetime, a conservative assumption that most likely overstates its yearly cost; nodes, for instance, routinely last more than 4 years. Maintaining the system could be done by the nursery irrigation manager; the labor cost is estimated at $\$ 1000$ per year, which is likely high (Table 2). Additional advanced consultation services are not included, as these would likely depend on size of an operation, the nature of the problem, and the level of services required by nursery, i.e., whether a site visit was necessary or whether phone and Internet consultations would be adequate.

\section{Results and discussion}

IRRIGATION SCHEDULING AND WATER USE. Typically, the grower scheduled two to four timed $(6 \mathrm{~min})$ irrigation events every 3 to $4 \mathrm{~h}$ during the day during summer for the grower-controlled trees (Fig. 5). This irrigation frequency decreased to one to two irrigations per day during early spring and fall, and irrigations were interrupted for $1-2 \mathrm{~d}$ when rainfall occurred. In contrast, as can be seen from early summer data (Fig. 6), the sensor-controlled trees were irrigated far less frequently than the trees irrigated with the cyclic irrigation regime (Fig. 5). This is significant, as this experienced irrigation manager was not only using his accumulated experience to supply the trees with adequate irrigation water but also was following recommended best management practices for minimizing nutrient leaching and interrupting cycles for rainfall.

For the 33-week study period (24 Mar. to 11 Nov. 2012), the average daily irrigation water applied by the grower-controlled irrigation to the dogwood trees was $0.92 \mathrm{gal} /$ tree, compared with $0.34 \mathrm{gal} /$ tree applied by the sensor-controlled irrigation (Table 1). Weekly average irrigation applications to the sensor-controlled dogwood trees were 1.4 to 6.5 times less than weekly applications to the grower-controlled trees (Fig. 7A), resulting in a reduction in irrigation water applications of $63 \%$ for this tree species. The sensor-controlled irrigation system, therefore, resulted in nearly a 3 -fold increase in efficiency (Table 1), without reducing growth or quality of the trees.

Table 2. Calculation of annualized hardware and setup costs for enterprise-wide irrigation monitoring and control sensor network. All sensors and nodes were obtained from Decagon Devices (Pullman, WA). Flow meter was obtained from Badger Meter (Milwaukee, WI).

\begin{tabular}{|c|c|c|c|c|c|}
\hline Item & No. & Price & Total & Lifetime (yrs) & $\begin{array}{c}\text { Annualized cost } \\
\text { at } 6 \% \text { interest }\end{array}$ \\
\hline \multicolumn{6}{|l|}{ Control system } \\
\hline nR5-DC (control) nodes & 8 & $\$ 675$ & $\$ 5,400$ & 3 & $\$ 1,967$ \\
\hline Em50R (monitoring) nodes & 8 & $\$ 675$ & $\$ 5,400$ & 3 & $\$ 1,967$ \\
\hline 10HS moisture sensors & 32 & $\$ 90$ & $\$ 3,200$ & 3 & $\$ 1,166$ \\
\hline Badger flow meters & 8 & $\$ 125$ & $\$ 1,000$ & 3 & $\$ 364$ \\
\hline ECNR-100 rain gauges & 8 & $\$ 300$ & $\$ 2,400$ & 3 & $\$ 874$ \\
\hline ES-2 (inline EC) sensors ${ }^{\mathrm{z}}$ & 8 & $\$ 225$ & $\$ 1,800$ & 3 & $\$ 656$ \\
\hline GS3 (substrate EC) sensors & 20 & $\$ 225$ & $\$ 4,500$ & 3 & $\$ 1,639$ \\
\hline $\begin{array}{l}\text { Weather station (Em50R node }+ \\
\text { environmental sensors) }\end{array}$ & 1 & $\$ 1,500$ & $\$ 1,500$ & 3 & $\$ 546$ \\
\hline Sensorweb and base station + computer & 1 & $\$ 600$ & $\$ 600$ & 3 & $\$ 219$ \\
\hline \multicolumn{6}{|l|}{ Monitoring system } \\
\hline Em50R (monitoring) nodes & 8 & $\$ 675$ & $\$ 5,400$ & 3 & $\$ 1,967$ \\
\hline Badger flow meters & 8 & $\$ 125$ & $\$ 1,000$ & 3 & $\$ 364$ \\
\hline 10HS moisture sensors & 32 & $\$ 100$ & $\$ 3,200$ & 3 & $\$ 1,166$ \\
\hline \multicolumn{6}{|l|}{ Installation } \\
\hline Equipment installation ${ }^{\mathrm{z}}$ & 1 & $\$ 10,738$ & $\$ 10,738$ & 30 & $\$ 772$ \\
\hline Setup consultation & 1 & $\$ 5,000$ & $\$ 5,000$ & 30 & $\$ 359$ \\
\hline Total & & & & & $\$ 14,025$ \\
\hline
\end{tabular}

${ }^{\mathrm{z}} \mathrm{EC}=$ electrical conductivity.

${ }^{y}$ Includes $3 \mathrm{~d}$ of use of a mini excavator rented at $\$ 150 / \mathrm{d}, 2 \mathrm{~d}$ use of a bobcat/trencher rented at $\$ 175 / \mathrm{d}, 250 \mathrm{~h}$ labor paid at $\$ 15 / \mathrm{h}, 40 \mathrm{~h}$ of management labor valued at $\$ 135 / \mathrm{h}$, and $\$ 2288$ in irrigation and equipment purchases. 
Similar results were seen for red maple trees, but differences in water applications between the growercontrolled and sensor-controlled irrigations were not as pronounced as in dogwood trees. The average daily irrigation water applied by the growercontrolled irrigation system was 1.72 $\mathrm{gal} /$ tree, compared with $1.13 \mathrm{gal} /$ tree applied by the sensor-controlled irrigation system (Table 1). This represented a $33 \%$ reduction in water applications over the year. The growercontrolled rows received more water for a large duration of the growing period, up to 5.2 times more water compared with the senor-controlled irrigation (Fig. 7B). However, there were instances when the sensorcontrolled irrigation system applied more water (up to 1.4 times) to the red maple trees compared with the grower-controlled irrigation system. This shows the flexibility of the sensor-controlled irrigation system and its ability to adjust to environmental conditions and tree canopy development, two major factors that influence daily and seasonal plant water use. As in dogwoods, the increase in diameter of the red maple trees in the grower-controlled and sensor-controlled rows was not different (Fig. 8A and B, respectively).

Profitability of switching FROM TIMED TO SENSOR-CONTROLLED IRRIGATION. In this specific situation, sensor-controlled irrigation application affected profitability in two ways: 1) by reducing the amount of water applied and 2) by reducing irrigation management time. These cost savings must then be compared with the cost of installing and operating the WSN system to obtain the net effect of sensor-controlled irrigation on profitability. Sensor-controlled irrigation eliminated the time spent monitoring field blocks and halved the time spent managing the irrigation control system each week. The value of those savings in management cost was calculated by multiplying the reduction in the amount of time spent managing the grower-controlled irrigation system by the manager's value of time. The nursery manager estimated time spent managing the irrigation system at $5 \mathrm{~h}$ per week over a 36-week growing season $(180 \mathrm{~h}$ per year, hence a savings of $90 \mathrm{~h}$ per year) and the value of his time at $\$ 135$ per hour.
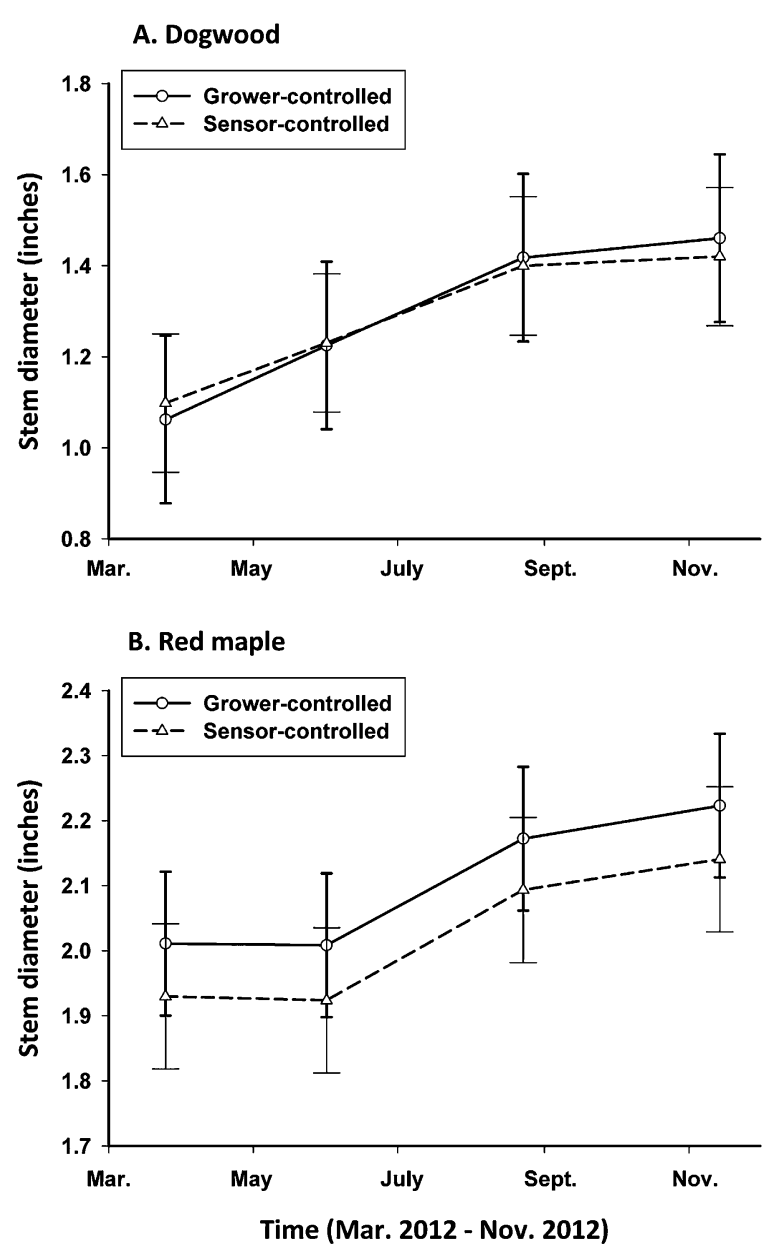

Fig. 8. Average increase in tree trunk diameter at 6-inch height for (A) dogwood and (B) red maple trees. Vertical bars (thick lines with narrow cap for grower-controlled trees and thin lines with wide cap for sensor-controlled trees) represent standard deviation about the mean. The grower-controlled rows were irrigated based on timed cyclic irrigation events scheduled by the grower as opposed to the sensor-controlled rows whose irrigation was independently controlled by the nR5-DC nodes (Decagon Devices, Pullman, WA). 1 inch $=2.54 \mathrm{~cm}$.

Switching to sensor-controlled of irrigation reduced water application by over half and eliminated the time spent managing the irrigation system, resulting in an annual savings of almost $\$ 20,300$ in irrigation expenditures (Table 3 ). The annualized cost of an enterprise-wide sensor-controlled irrigation system is just over $\$ 14,000, \approx 4 / 5$ of the annual savings in irrigation-related expenditures. Adding the annual costs of maintaining the sensor system, we find that switching to sensor control increases whole farm profit by about $\$ 5300$ per year. The rate of return on investment in the system, which equals the annual savings in irrigation costs less the annual cost of consultant services, all divided by the annualized cost of purchasing and installing the sensor-controlled system was $37.5 \%$. Based purely on pumping costs and the reduction in the irrigation manager's time, the sensor

Table 3. Profitability of changing timed cyclic irrigation into sensorcontrolled irrigation.

\begin{tabular}{lr}
\hline Item & \multicolumn{1}{c}{$\begin{array}{c}\text { Annual } \\
\text { cost }\end{array}$} \\
\hline Irrigation savings & \\
$\quad$ Pumping cost savings & $\$ 8,138$ \\
$\quad$ Management cost savings & $\$ 12,150$ \\
$\quad$ Annual irrigation savings & $\$ 20,288$ \\
Sensor system cost & \\
$\quad$ Control system & $\$ 9,397$ \\
$\quad$ Monitoring system & $\$ 3,497$ \\
$\quad$ Initial installation & $\$ 772$ \\
Initial setup consultation & $\$ 359$ \\
$\quad$ Yearly maintenance (labor) & $\$ 1,000$ \\
$\quad$ Total sensor system & $\$ 15,025$ \\
Annual net savings & $\$ 5,263$ \\
\hline
\end{tabular}


network would therefore pay for itself in 2.7 years out of its assumed 30-year lifetime, taking into account replacement of some equipment every 3 years.

Savings in water costs accounted for only a quarter of these savings. However, the nursery pumps water directly from an adjacent river and pays only the cost of pumping. Pumping costs are relatively low for this grower due to low electricity prices, so that even very substantial reductions in water use result in very modest reductions in direct water-related expenses. Water savings are likely to be much more valuable in regions where water is more costly, e.g., for nurseries paying municipal water rates, pumping water from deep wells, or facing tight constraints on water availability (in which case the implicit cost of water is high). To illustrate this point, Table 4 shows the profitability of switching from timed to sensor-controlled irrigation over a range of water price rates spanning levels charged by utilities in California, assuming the same water use, water savings, and savings in management time as experienced in Tennessee. For nurseries paying municipal water rates, savings in water charges dwarf the value of savings in management time. The value of water savings is as much as 15 times higher than in Tennessee, whereas profitability is as much as 22 times higher (Table 4). Assuming a nominal cost for water of $\$ 326$ per acre-foot of water (Table 4 ), the payback period on a similar sensor network in this case would be less than 4 months.

The reduction in management time accounted for $3 / 4$ of the savings from sensor-controlled irrigation.
Although the value of management time assumed here may seem high, management time is always very valuable because the demand on managers' decision-making ability is always large. When the cost of water is as low as in Tennessee, installing sensor-controlled irrigation remains profitable as long as irrigation management labor of a quality similar to that in Tennessee is valued at more than $\$ 58$ per hour. In operations where irrigation management is delegated to field labor, the hourly labor rate may be lower but the quality of decision making and the timeliness of irrigation decisions may be very much lower as well. Embedded in these poorer decisions are additional water costs, the cost of nutrient leaching (both direct costs to the farmer and long-term costs to the environment), all of which add up to an effective cost that can be substantially higher than the nominal hourly labor rate. In such cases, switching to sensorcontrolled irrigation will result in greater savings in water and fertilizer costs than assumed here.

Taken together, these results suggest that sensor-controlled irrigation is likely to be extremely profitable in areas where the cost of water is high, in operations where irrigation efficiency is currently low, and in operations where management time is extremely valuable. Water rates are high at present in California and the southwestern United States, which account for substantial shares of nursery and greenhouse operations. Growing water scarcity is driving up the explicit and implicit costs of surface water in the southeastern United States and High Plains as well and many operations throughout the

Table 4. Water price comparisons and returns from changing timed cyclic irrigation into sensor-controlled irrigation.

\begin{tabular}{|c|c|c|c|c|}
\hline \multirow[b]{2}{*}{ Costs and benefits } & \multicolumn{4}{|c|}{ Water price $\left[\text { per } 1000 \mathrm{gal}\left(3.785 \mathrm{~m}^{3}\right)\right]^{\mathrm{z}}$} \\
\hline & $\$ 0.17$ & $\$ 1.00$ & $\$ 2.00$ & $\$ 3.00$ \\
\hline \multicolumn{5}{|l|}{ Benefits } \\
\hline Pumping cost savings & $\$ 8,137$ & $\$ 46,944$ & $\$ 94,189$ & $\$ 141,283$ \\
\hline Management cost savings & $\$ 12,150$ & $\$ 12,150$ & $\$ 12,150$ & $\$ 12,150$ \\
\hline Annual savings & $\$ 20,288$ & $\$ 59,094$ & $\$ 106,339$ & $\$ 153,433$ \\
\hline \multicolumn{5}{|l|}{ Costs } \\
\hline $\begin{array}{l}\text { Annualized sensor } \\
\text { system cost }\end{array}$ & $\$ 14,205$ & $\$ 14,205$ & $\$ 14,025$ & $\$ 14,025$ \\
\hline Annual maintenance & $\$ 1,000$ & $\$ 1,000$ & $\$ 1,000$ & $\$ 1,000$ \\
\hline Total sensor system cost & $\$ 15,205$ & $\$ 15,205$ & $\$ 15,025$ & $\$ 15,025$ \\
\hline Annual net savings & $\$ 5,263$ & $\$ 44,069$ & $\$ 91,313$ & $\$ 138,408$ \\
\hline
\end{tabular}

country draw water from deep wells and thus incur high pumping costs. It is thus likely that investing in sensor-controlled irrigation will be profitable for a large number of operations throughout the United States and Canada. Associated issues where the growth of plants is impacted due to water stress and root diseases (caused by both over- and underirrigation) are also factors which we believe will greatly impact the use and profitability of these automated sensor-controlled irrigation systems in the future.

\section{Conclusions}

In this study, we used sensorbased set-point irrigation control with two species of trees to automatically control irrigation schedules within a commercial nursery operation over an entire growing season. This independent, sensor-based irrigation system reduced daily water applications to dogwood and red maple trees by $63 \%$ and $33 \%$ of the water applied by an experienced irrigation manager, without affecting the growth of either species. Despite the cost of water being minimal for this particular operation, significant time was saved in daily irrigation management, which translated into an annual net savings of $\$ 5263$ for this operation and a payback period of 2.7 years. This research is ongoing and will identify other costs and benefits of using sensor network installations in container-nursery tree production.

\section{Literature cited}

Bacci, L., P. Battista, and B. Rapi. 2008. An integrated method for irrigation scheduling of potted plants. Sci. Hort. 116:89-97.

Bunt, A.C. 1961. Some physical properties of pot-plant composts and their effect on plant growth. Plant Soil 13:322-332.

Cobos, D.R. and C. Chambers. 2010. Calibrating $\mathrm{ECH}_{2} \mathrm{O}$ soil moisture sensors. Decagon Devices Application Note 13393-04. 15 Aug. 2013. <http://www. decagon.com/assets/Uploads/13393-04CalibratingECH2OSoilMoistureProbes. pdf $>$.

Dunkelberg, W.C. and H. Wade. 2013. Small business credit conditions: Actual interest paid on short term loans by borrowers. Natl. Federation Independent Business Res. Foundation, Nashville, TN. 
Fereres, E.D., A. Goldhamer, and L.R. Parsons. 2003. Irrigation water management of horticultural crops. HortScience 38:1036-1042.

Jones, H.G. 2008. Irrigation scheduling Comparison of soil, plant and atmosphere monitoring approaches. Acta Hort. 792:391-403.

Kohanbash, D., A. Valada, and G. Kantor. 2011. Wireless sensor networks and actionable modeling for intelligent irrigation. Amer. Soc. Agr. Biol. Eng., Louisville, KY, 7-12 Aug. 2011. Paper No. 1111174.

Kohanbash, D., A. Valada, and G. Kantor. 2012. Irrigation control methods for wireless sensor networks. Amer. Soc. Agric. Biol. Eng., Dallas, TX, 29 July-1 Aug. 2012. Paper No. 121337112.
Kohanbash, D., G. Kantor, T. Martin, and L. Crawford. 2013. Wireless sensor network design for monitoring and irrigation control: User-centric hardware and software development. Hort Technology 23:725-734.

Lea-Cox, J.D. 2012. Using wireless sensor networks for precision irrigation scheduling, p. 233-258. In: M. Kumar (ed.). Problems, perspectives and challenges of agricultural water management. InTech Press. Rijeka, Croatia.

Lea-Cox, J.D., A.G. Ristvey, D.S. Ross, and G.F. Kantor. 2009. Deployment of wireless sensor networks for irrigation and nutrient management in nursery and greenhouse operations. Proc. Southern Nursery Assn. Res. Conf. 54:28-34.

Lea-Cox, J.D., D.S. Ross, and K.M. Teffeau. 2001. A water and nutrient management planning process for container nursery and greenhouse production systems in Maryland. J. Environ. Hort. 19:230-236.

Majsztrik, J.C., A.G. Ristvey, and J.D. Lea-Cox. 2011. Water and nutrient management in the production of container-grown ornamentals. Hort. Rev. 38:253-296.

Ross, D.S., J.D. Lea-Cox, and K.M. Teffeau. 2001. The importance of water in the nutrient management process. Proc. Southern Nursery Assn. Res. Conf. 46:588-591.

van Iersel, M.W., M. Chappell, and J.D. Lea-Cox. 2013. Sensors for improved efficiency of irrigation in greenhouse and nursery production. Hort Technology 23:735-746. 